\title{
ENTREVISTA COM O ATIVISTA PELOS DIREITOS DA CAUSA LGBTTI
}

\author{
Por Raquel Simone Varaschin
}

João W. Nery é graduado em psicologia pelo Instituto de Psicologia da Universidade Federal do Rio de Janeiro (UFRJ), professor universitário, psicoterapeuta e pesquisador em Gênero, especialista em Sexologia pelo Instituto Estadual de Diabetes e Endocrinologia (IEDE). Ativista pelos direitos da causa LGBTTI.

I. Primeiro você publicou o livro autobiográfico Erro de pessoa: João ou Joana, no qual você narra sua transexperiência, seus conflitos e angústias vividas desde sua infância dentro de uma sociedade que discrimina o "diferente". No segundo livro autobiográfico: Viagem solitária: memórias de um transexual 30 anos depois, você aborda sobre as "várias masculinidades diferentes e que são constituídas também pelas tecnologias da cultura dominante". Como você avalia as transformações sociopolíticas ocorridas durante a sua trajetória como primeiro transhomem operado no Brasil? E sobre o Projeto de Lei "João Nery" que tramita na Câmara dos Deputados desde 2013, que busca garantir à população trans o reconhecimento da sua identidade de gênero?

João W. Nery: Desde a ressignificação de termos como transformistas e entendidos, empregados durante a ditadura militar, que eram considerados pervertidos, criaturas perigosas e contaminadores da juventude, até a criação do personagem transexual pela Medicina em meados do século $X X$, houve um grande avanço na visibilidade dos LGBTs. Em 1995 criou-se em Cuiabá-MT, o Movimento Transexual Brasileiro, a primeira associação de defesa e lutas pelos direitos deste segmento. Em outubro de 1993 saiu a primeira parada LBGT no Brasil, em Copacabana, com poucos participantes e todos mascarados. Hoje se espalharam por todo o país, avançando a visibilidade da diversidade sexual, assim como foram criadas nas redes sociais múltiplos vídeos, blogs, ONGs. Em 2008 o SUS começou efetivamente o processo transexualizador operando um trans por mês em cada hospital credenciado. Hoje são 5, sendo 2 com as inscrições fechadas (RJ e SP). A falta de informação sobre este segmento é enorme, sobretudo quando ainda se confunde identidade de gênero com orientação sexual. Consequência esta das pouquíssimas universidades que têm em seu currículo a cadeira de "Gênero e Sexualidade", acarretando um total despreparo dos profissionais para lidar com os trans. Ultimamente a mídia vem divulgando mais esta questão em função da telenovela "A força do querer" da Gloria Perez, que, inspirada no livro Viagem solitária, aborda a questão das transmasculinidades. O IBRAT - Instituto Brasileiro de Transmasculinidades, desde 2013 incluiu também os gêneros fluidos, não binários ou queers, que não querem ser rotulados e são contrários ao binarismo de gênero. Apesar de em 2011 o Supremo Tribunal Federal reconhecer, por unanimidade, a união estável entre casais do mesmo sexo como entidade familiar, a violência ficou mais permissiva e evidente. 0 Brasil continua liderando o ranking de morte de LGBTs, seguido do México, com quatro vezes menos. Um dos maiores problemas para a população transgênera continua sendo a falta de uma legislação de reconhecimento e protetora dos seus direitos civis. O nome social, além de não vigorar na maioria dos estados brasileiros, não é cumprido como deveria. Para preencher essa lacuna, os deputados federais Jean Wyllys e Érika Kokay protocolaram na Câmara, em 20 de fevereiro de 2013, o projeto de lei 5002, com o nome de Lei João W. Nery ou Lei de Identidade de Gênero (WYLLYS, KOKAY, 2013). O projeto de lei, em resumo, garante o direito do reconhecimento à identidade de gênero de todas as pessoas trans no Brasil, sem necessidade de autorização judicial, laudos médicos ou psicológicos, cirurgias, hormonioterapias. Preserva todo o histórico, assegura o acesso à saúde no processo de transexualização, despatologiza as trans identidades para a assistência à saúde e preserva o direito à família frente as mudanças no registro. Propõe, assim, que a psicoterapia só seja feita caso o interessado assim o desejar. O projeto foi feito com base na experiência da Lei de Identidade de Gênero argentina (aprovada por unanimidade no senado argentino). Atualmen- 
te, vivemos um retrocesso político que trouxe o conservadorismo e uma influência neopentecostal dominante no Congresso e na sociedade em geral, invadindo quase todos os campos, o que dificultará a aprovação da Lei de Identidade de Gênero num plenário tão avesso aos direitos humanos.

\section{No seu livro Viagem Solitária você cita Kurt} Lewin, que defendia a ideia que o comportamento é função da interação entre pessoa e ambiente. Ao realizar a mamoplastia masculinizadora e a pan-histerectomia em 1977, época da ditadura militar e $\mathbf{2 0}$ anos antes das cirurgias serem legalizadas, como você foi influenciado pelo ambiente que o cercava, e como você influenciou o ambiente que vivia?

João W. Nery: Eu lia muito os antropólogos culturalistas e cada vez mais confirmava o que sempre defendi, que só se vira humano depois da linguagem. Aliás, nem corpo pré-linguístico pode existir.

Conversando com uma amiga sexóloga, soube da equipe do Hospital Moncorvo Filho que iniciava no Brasil estudos pioneiros sobre transexualismo. Tudo feito às escondidas e criminosamente. Um desafio para uma época que ouvi muitos "nãos", mas sei que rompi barreiras quase intransponíveis. Mais por necessidade do que por coragem. O que influenciei o ambiente, só a história e o tempo dirão, mas com certeza, dei visibilidade para as transmasculinidades.

3. Aos $\mathbf{3 7}$ anos, você viveu a paternidade, assumindo Yuri como seu filho, o qual sempre se revelou apaixonado e grato pelo pai que o acompanhou, deu amor incondicional, foi ouvinte, orientador, e que procurou não repassar condutas e atributos de gênero. $\mathrm{Na}$ discussão sobre homem grávido junto com seus amigos trans, aparece claramente a dificuldade de lidar com o "diferente" do que se espera de um transhomem e em estabelecer parâmetros do que pertence ao feminino e ao masculino ao gerar um filho. Qual é a sua avaliação a respeito?

João W. Nery: Esta é uma questão polêmica mesmo dentro do segmento transmasculino, em que muitos apresentam ainda o machismo - essa epidemia sócio-patológica assassina. Porém já existem no mundo vários transhomens grávidos, ou por viverem com transmulheres ou por terem feito inseminação artificial. Como menciono no meu último livro Vidas Trans: a coragen de existir (Ed. Astral Cultural, 2017), é necessário ter um programa alternativo para futuras reproduções antes das cirurgias de esterilização. Proporcionaria para os que quisessem futuramente ter filhos biológicos, poderem congelar o próprio sêmen/óvulos. Seriam abertas as portas da Ginecologia e da Obstetrícia para que não fossem consideradas especialidades unicamente femininas. Assim o sistema informatizado do SUS poderia ler nomes masculinos (no caso dos transhomens) sem classificar como fraude, como acontece hoje. Sou completamente favorável à desmistificação da naturalização da mater/paternidade como um dado inato e estereotipado, mas pessoalmente, acho a gravidez um desgaste físico brutal. Devíamos ter filhos pelos dedos, como dizia meu amigo Darcy Ribeiro.

\section{As cicatrizes físicas retrataram a realização e satisfação de uma identidade física que compor- tasse sua identidade de gênero. Quais são as cica- trizes emocionais que resultaram desse processo de reconstrução?}

João W. Nery: A principal foi poder ser lido pelos outros como eu me sentia. Mais feliz, com uma autoestima mais elevada, uma maior humanidade e disposto a ajudar os discriminados. A única fragilidade foi a perda do meu diploma, o que me acarretou consequências de dependência financeira e não ter uma estabilidade de emprego nem de aposentadoria.

5. A partir da publicação de sua autobiografia, como ela contribuiu para o avanço dos estudos sobre transexualidade e para visibilidade das diversas sexualidades?

João W. Nery: O compartilhamento da minha história possibilitou a muitas pessoas se identificarem comigo ou identificarem seus amigos e parentes, dentre outros. A procura por ajuda em todos os níveis foi tão grande, que me vi obrigado a me familiarizar com as redes sociais para atender aos diversos pedidos provenientes de pais de pessoas trans, que me pediam orientação; de filhos que não sabiam como se assumir perante a sociedade ou para os parentes; de transhomens que até então se autodeclaravam lésbicas masculinas, por desconhecerem outras categorias, alguns dos quais já tinham tentado suicídio e viviam à base de antidepressivos; de indicação de profissionais especializados. Até he- 
terossexuais homofóbicos e transfóbicos vieram me agradecer por terem se libertado do preconceito com a leitura do livro, o que me fez sentir que havia me tornado uma espécie de psicólogo virtual. A partir dos meus contatos pelo Facebook com trans do Brasil inteiro, estou fazendo uma espécie de primeiro censo de transmasculinidades e registrei, até junho de 2017, cerca de 3.500 em 26 estados. Atualizei-me sobre os mais recentes estudos sobre o gênero. Escrevi vários artigos sobre transmasculinidades, que estão publicados em revistas acadêmicas, em co-autorias, por não possuir um currículo lattes.

\section{Carol Duarte, atriz da novela A força do querer} interpreta uma personagem trans-homem, cujo trama foi escrito por Glória Perez, e uma de suas fontes de pesquisa teria sido sua autobiografia. Como você avalia esse movimento da sociedade levando para diversos públicos conhecimentos sobre a realidade transgênero?

João W. Nery: Acho maravilhoso. Faz-se necessário um esclarecimento urgente da transgeneridade, possibilitando uma visão renovada das identidades não cisheteronormativas para a população. Família, escola, trabalho, profissionais principalmente os da saúde precisam se conscientizar da importância de encarar novas realidades e entender o respeito que este segmento merece.

7. O DSM-5 substituiu o termo "transtorno de gênero" para "disforia de gênero", mantendo a patologização ou psiquiatrização das transidentidades. Mas cientistas mexicanos realizaram o primeiro estudo de campo que demonstra que as mudanças na identidade de gênero não são uma doença. $O$ estudo, publicado na revista médica britânica The Lancet Psychiatry, é o primeira de vários que já estão sendo feitos no Brasil, França, Índia, Líbano e África do Sul, e que serão apresentados em 2018 na discussão da I I ${ }^{a}$ versão da Classificação Internacional de Doenças (CID-I I) da OMS. Como você vê esse movimento para o desenvolvimento de políticas de saúde mais adequadas e para a desestigmatização?

João W. Nery: Desde 2010, com a Campanha Internacional Stop Trans Pathologization, o mundo se mobilizou para retirar da classificação de transtorno mental ou disforia de gênero nos catálogos diagnósticos. E a APA é até hoje a "definidora-chefe" para o resto do mundo. Apesar das inúmeras leis de identidade de gênero em vários países europeus e sul-americanos, todos exigem ainda o laudo psiquiátrico para a transição, inclusive a França, que fez uma "despatologização burocrática". Somente a Argentina é que dispensou na sua lei o laudo. Além do mais, manter os trans doentes favorece o lucro dos laboratórios farmacêuticos, fortalece a "cisheteronormalidade" e a "sanidade" para os cisgêneros. É importante questionarmos o protocolo do SUS que impõe aos trans que se submetam, "obrigatoriamente", por dois anos, a testes, psicoterapias e questionários sexistas. Há estudos sérios que comprovam o "teatro" que são as psicoterapias no processo transexualizador do SUS, como o do Prof. Rodrigo Borba, que em 2016 publicou pela Fiocruz seu livro $O$ (des) aprendizado de si: transexualidades, interação e cuidado em saúde. Nele são gravadas várias sessões demonstrando como os padrões dos profissionais de saúde, quanto ao que é masculino e feminino, são impostos aos pacientes de forma estereotipada para que consigam obter o laudo necessário à transição. Os trans tomam conhecimento de antemão do que deverão dizer e como se comportar para serem aceitos, visando atender às expectativas binaristas do que é ser um "transexual verdadeiro". São esses "especialistas" cisgêneros que farão o diagnóstico que dirá quem ele/a é e se poderão ou não mexer em seus corpos. Essa visão é binarista e autoritária, igualando a todos e não reconhecendo nuances e diferenças.

Ser um "disfórico de gênero" pode também ser visto por alguns trans como uma isenção de responsabilidade sobre sua própria condição. Entretanto, aceitar esse rótulo é abrir mão da sua própria autonomia,

Outra consequência grave de considerar a transexualidade uma patologia, colocando o gênero como uma categoria diagnóstica, é a pressão exercida sobre crianças e adolescentes trans, que são levados a se ver como doentes. É muito séria a internalização da transfobia, transformando o sofrimento de seres frágeis, ainda em formação, em alvos merecedores de punição ou praticantes de pecado. Como diz um amigo meu: "ser patologizado é fazer escambo com sua dignidade, é autorizar outrem a tutelar nossas vidas e corpos, é doar aos nossos inquisidores e carrascos o chicote que nos violenta com suas definições, laudos, testes, comprovações e todas as artimanhas".

"Há algum tempo o DSM vem sendo anali- 
sado como uma peça de controle social, discurso moralista disfarçado em pele científica. Por que psiquiatras insistem em falar e normatizar questões que dizem respeito ao direito do sujeito à autodeterminação?" (Bento, 2016).

Acrescento algumas conclusões da Dra, Berenice Bento do seu pós-doc nos Estados Unidos sobre o GT que estuda o DSM5:

"A composição do GT transtornos sexuais e de identidade de Gênero do grupo de estudos e de consultores é basicamente formada por pesquisadores estadunidenses e psiquiatras. $\mathrm{E}$ há um total desinteresse por outros contextos culturais e significados para as múltiplas expressões de gênero; a concepção de gênero está fundada na noção dimórfica dos corpos sexuais; as referências bibliográficas são endogâmicas, os membros do GT citam uns aos outros, resultando na produção intencional de um cânone; ausência de qualquer validade científica. Não existe nenhuma pesquisa aceita que assegura a determinação biológica para a origem das identidades do gênero, conforme o próprio GT reconhece e, por fim, a dimensão violenta do texto está em tentar ler a diversidade das expressões de gênero pela lupa de uma cultura específica."

\section{8. $O$ que você diria hoje para alguém que está iniciando o processo pelo qual você passou? E o que diria para os familiares que acompanharão essa trajetória de vida?}

João W. Nery: Orgulhem-se de serem transexuais, pois somos resistência ao biopoder, Nossos corpos são políticos, pura transcendência de querer ser o que desejamos. Nascemos como uma flor rara do pântano desta hipocrisia social que, preocupada em se definir como "normal", aponta o dedo em riste para nos culpar, adoentar, visando enfatizar a genitalização como responsável pela definição do gênero, alegando uma naturalização e uma universalidade fictícia para discriminar, lucrar, hierarquizar e se tornarem possuidores de um biopoder ilusório de perfeição. Quanto aos familiares confusos, aconselharia procurar grupos de pais que há no Facebook (em todos os estados), como os da Mães pela Diversidade (https://www.facebook.com/groups/842555495786499/), que dão apoio e eslarecimentos aos pais de LBGTs.

\section{Considerações finais}

João W. Nery: Como escritor e ativista sigo na perspectiva de que minha experiência e meu testemunho possam colaborar para a (trans) formação da subjetividade das novas gerações, construindo uma sociedade mais aberta, democrática e respeitosa aos direitos da diversidade, em que cada um, enfim, poderá ser livre para dizer: "Eu sou o que eu quiser".

Raquel Simone Varaschin - Psicóloga. Pós-graduada em Sexualidade Humana, formação em terapia de casal e pós-graduada e especialista em Neuropsicologia. Vice-presidente da SBRASH - Gestão 2016-2017. Membro da ISSM, SLAMS e FLASSES.

\section{Contato}

http://www.youtube.com/playlist?list=PL6A63F8F2 65F760DF\&action_edit $=1 \&$ feature $=$ view_al.

Alguns artigos:

https://independent.academia.edu/ Jo\%C3\%A3oWalterNery.

Perfil no FACEBOOK: https://www.facebook.com/ JWNery

Tel: (21) 26217951 